\title{
Aporte de fitomassa pelas sucessões de culturas e sua influência em atributos físicos do solo no sistema plantio direto
}

\author{
Denis Augusto da Silva ('); Luiz Carlos Ferreira de Souza (2*); Antonio Carlos Tadeu Vitorino (2); \\ Manoel Carlos Gonçalves $\left({ }^{2}\right)$ \\ (') Rua Camilo E. da Silva, 1308, 79826-070 Dourados (MS).E-mail: denisaugusto@douranet.com.br \\ (2) Universidade Federal da Grande Dourados, Faculdade de Ciências Agrárias. Rua João Rosa Góes, 1761, 79825-070 Dourados \\ (MS).E-mail: luizsouza@ufgd.edu.br (*) Autor correspondente; vitorino@ufgd.edu.br; manoel.goncalves@ufgd.edu.br
}

Recebido: 23/jan./2009; Aceito: 18/fev./2010

\begin{abstract}
Resumo
A degradação física dos solos, como a compactação, reduz a movimentação de água e o crescimento de raízes. A estrutura do solo é considerada como uma de suas mais importantes propriedades do ponto de vista agrícola, pois a ela estão relacionadas outras propriedades fundamentais nas relações solo-planta. Com o objetivo de se avaliar o efeito de culturas de cobertura nos atributos físicos do solo realizou-se este trabalho em um Latossolo Vermelho Distroférrico, textura muito argilosa, nas safras de 2004/2005 e 2005/2006, na Universidade Federal da Grande Dourados, em uma área há oito anos sob plantio direto. $\mathrm{O}$ delineamento experimental foi em blocos completamente casualizados com três repetições. Foram avaliadas as culturas girassol (Helianthus annuus L.), crotalária (Crotalaria juncea L.), ervilhaca peluda (Vicia villosa Roth), consórcio de crotalária e aveia preta (Avena strigosa Schreb) e consórcio de aveia preta, ervilhaca peluda e nabo forrageiro (Raphanus sativus L. var. oleiferus Metzg), sucedendo a soja e como antecessoras do milho. As culturas de girassol, crotalária e o consórcio aveia preta mais crotalária proporcionaram maiores teores de carbono orgânico total; os valores de macroporosidade e porosidade total aumentaram na camada superficial enquanto os valores de densidade do solo e de microporosidade foram menores nessa camada. Os agregados foram mais estáveis na camada $0-5 \mathrm{~cm}$. Os sistemas de culturas estudados foram eficientes na produção de palha, capazes preservar os atributos físicos do solo. Os consórcios entre aveia preta+ervilhaca peluda+nabo forrageiro e, da aveia preta+crotalária possibilitam maior cobertura e permanência da palha sobre o solo.
\end{abstract}

Palavras-chave: culturas de cobertura, agregação, porosidade, densidade.

\section{Phytomass contribution by the culture successions and its influence on physical characteristics of the soil in no till}

\section{Abstract}

Soil physical degradation, like compaction, reduces water movement and root development. Soil structure is considered one of most importance to agriculture and closely related to it are other fundamental properties in soil-plant relationship. The objective of this study was to evaluate the effect of crop sequences on physical attributes. The research was realized in 2004/05 and 2005/06 growing seasons, in a Typic Clayey Rhodic Hopludox, under eight years of no-tillage system, at Dourados (MS). The experiment was a randomized complete block design, with three replications. Treatments were constituted by cover crops: sunflower (Helianthus annuus L.), sunnhemp (Crotalaria juncea L.), hairy vetch (Vicia villosa Roth), mixture of sunnhemp + black oat (Avena strigosa Schreb), and mixture of black oat + hairy vetch + oilseed radish (Raphanus sativus L. Var. oliferus Metzg). Differences were not observed in soil density, porosity and aggregation rate when it was cultivated with sunflower, hairy vetch, sunnhemp, or the mixtures. Differences were observed in soil physical properties between 0-5 cm layer and 5-10cm - 10-20 $\mathrm{cm}$ layers, but no differences between $5-10 \mathrm{~cm}$ and $10-20 \mathrm{~cm}$ layers. Soil carbon trend to higher contents in crops with high production of surface residues, although differences in carbon contents were insufficient to modify aggregation.

Key words: cover crops, aggregation, porosity, bulkdensity. 


\section{INTRODUÇÃO}

Os atributos físicos do solo são alterados pelo manejo, e sistemas que proporcionam aumento do teor de carbono orgânico do solo também promovem maiores valores de diâmetro médio ponderado de agregados (BERTOL et al., 2004). Pesquisa desenvolvida por KusHWAHA et al. (2001) observaram maiores proporçôes de macroagregados quando este foi mantido com resíduos vegetais na superfície e sem preparo do solo. SiLva et al. (2000) encontraram na camada superficial do solo os maiores valores de índice de floculação e de agregados maiores que $2 \mathrm{~mm}$, tanto em mata nativa como em Sistema Plantio Direto (SPD), sendo estes valores relacionados com os maiores teores de matéria orgânica.

Um dos fatores imprescindíveis para a implantação e manutençáo do SPD é a presença de cobertura vegetal morta para proteger o solo, planejado dentro de um sistema de rotação de culturas (KochHann, 1996). A manutenção de restos culturais na superfície do solo, em um sistema de rotação de culturas, é importante fator para propiciar melhorias na estrutura do solo, refletindo na infiltração de água, redução da temperatura superficial do solo e aumento da estabilidade dos agregados (Floss, 2000).

A introdução de plantas de cobertura intercalar ao milho demonstrou no trabalho de Argenton et al. (2005) ser uma prática benéfica para as propriedades relacionadas com a estrutura do solo, sendo a mucuna cinza mais promissora que guandu anão, visto que aumentou a macroporosidade, a porosidade total e a condutividade hidráulica, além de reduzir a densidade do solo. WoHLENBERG et al. (2004), trabalhando com diferentes sistemas de sucessóes e rotaçóes de culturas, concluíram que a maior percentagem de agregados ocorreu quando o solo foi mantido com cobertura vegetal durante todo o ano. A compactaçáo do solo pode prejudicar o desenvolvimento do sistema radicular e consequentemente o desenvolvimento da planta. Rosolem et al. (1999) observaram que o desenvolvimento da raiz seminal e das raízes adventícias de milho é diminuído em maiores densidades do solo. Por outro lado, as raízes podem atuar como agentes recuperadores da física do solo. A utilização de espécies com diferentes características de sistema radicular, que podem ser incluídas em sistema de rotação e/ou sucessão, é importante para o planejamento da recuperação de áreas degradadas (Teixeira et al., 2003).

$\mathrm{O}$ uso de culturas que favorecem a agregação pode minimizar os efeitos negativos da degradação dos solos, porém, informaçôes sobre quais sistemas de culturas são mais apropriados ainda são incompletos (WoHLENBERG et al., 2004). As raízes de Crotalaria juncea, por exemplo, podem crescer em camadas de solo compactado e desenvolver maior número e raízes laterais finas nesta camada, contribuindo assim para a formação de bioporos e melhorando as condiçôes físicas do solo (FolONI et al., 2006).

As crucíferas têm um desenvolvimento radicular que permite maior exploração do solo e consequentemente favorece as culturas cultivadas em sucessão. Williams e WeIL (2004), por análise de imagens, observaram raízes de soja em solo compactado, se desenvolvendo-se nos bioporos deixados por raízes de nabo forrageiro (Raphanus sativus) e canola (Brassica rapa), demonstrando o benefício que culturas antecessoras podem trazer às subsequentes. $\mathrm{A}$ aveia preta (Avena strigosa) tem sido muito utilizada como cobertura do solo em plantio direto, principalmente pela sua elevada produção de palha, supressão de plantas daninhas e melhorias nas características físicas do solo, como diminuição da densidade do solo, aumento da macroporosidade e aumento da infiltração de água (SANTI et al., 2003).

O objetivo desta pesquisa foi avaliar os atributos físicos do solo, em função do cultivo de diferentes espécies vegetais, semeadas no verão ou no inverno em um experimento de longa duração.

\section{MATERIAL E MÉTODOS}

Este trabalho foi realizado no município de Dourados (MS), situado na latitude de $22^{\circ} \mathrm{I} 4^{\prime} \mathrm{s}$ e longitude $54^{\circ} 49^{\prime}$ w, com $452 \mathrm{~m}$ de altitude. O solo é classificado como Latossolo Vermelho Distroférrico, textura muito argilosa ( $80 \%$ de argila, $14 \%$ de silte e $6 \%$ areia), originalmente sob vegetação de cerrado, sendo cultivada desde $1997 \mathrm{em}$ sistema plantio direto. Durante esses anos, os tratamentos se caracterizaram por estudar sistemas de produção, utilizando no verão as culturas de soja e milho, e no inverno, várias espécies para produção de grãos ou de palha, em sucessão ou rotação. Os dados apresentados nesse trabalho referem-se aos anos agrícolas de 2004/2005 e 2005/2006 e foram avaliadas as diferentes culturas em sucessão a soja e ao milho.

O delineamento experimental foi em blocos completos casualizados, contendo dez tratamentos, com três repetições. Os tratamentos foram constituídos pelas parcelas que continham as seguintes culturas de inverno: girassol (Helianthus annuus L.), crotalária (Crotalaria juncea L.), ervilhaca peluda (Vicia villosa Roth), consórcio de crotalária e aveia preta (Avena strigosa Schreb) e consórcio de aveia preta, ervilhaca peluda e nabo forrageiro (Raphanus sativus L. var. oleiferus Metzg), semeadas em sucessão as culturas da soja e do milho respectivamente, conforme a tabela 1 .

As culturas de inverno foram semeadas em maio, utilizando-se semeadoras equipadas para plantio direto, em parcelas de $12 \mathrm{~m}$ de largura por $36 \mathrm{~m}$ de comprimento. O girassol foi semeado em espaçamento de $0,9 \mathrm{~m}$ com sete sementes por metro linear; a crotalária foi semeada 
em espaçamento de $0,45 \mathrm{~m}$ com 12 sementes por metro linear; a ervilhaca peluda foi semeada em espaçamento de $0,34 \mathrm{~m}$ com 20 sementes por metro linear. O consórcio de crotalária e aveia preta foi feito semeando-se primeiramente a aveia, em espaçamento de $0,17 \mathrm{~m}$, com densidade de 50 sementes por metro linear, e a crotalária foi semeada sobre a aveia preta no espaçamento de $0,45 \mathrm{~m}$ com 12 sementes por metro linear. O consórcio de aveia preta, ervilhaca peluda e nabo forrageiro foi feito pela mistura física das sementes na proporção de $50 \%, 40 \%$ e $10 \%$ respectivamente. A mistura foi semeada em espaçamento de $0,17 \mathrm{~m}$ com densidade em torno de 50 sementes por metro linear.

Em agosto, foi realizado o manejo mecânico das culturas com 'rolo-faca'. A aveia preta, o girassol e o nabo forrageiro estavam na fase de grão leitoso. A ervilhaca peluda e a crotalária estavam em pleno florescimento. O milho híbrido DKB 390 foi semeado mecanicamente em 27 de outubro de 2004 e 28 de outubro de 2005 para o primeiro e segundo ano respectivamente, sendo a população de plantas de 55.000 plantas por hectare. A adubação de semeadura foi feita no sulco, na dose de $300 \mathrm{~kg} \mathrm{ha}^{-1}$ da fórmula 08-20-20; a adubação de cobertura foi feita na fase de seis folhas completamente desenvolvidas, com $220 \mathrm{~kg} \mathrm{ha}^{-1}$ de uréia.

Em pleno florescimento das culturas de inverno, foram retiradas amostras da parte aérea, utilizando-se uma armaçáo metálica de $0,5 \mathrm{~m}^{2}$ lançada ao acaso em três pontos por parcela. As amostras foram secas em estufa a $65^{\circ} \mathrm{C}$ até massa constante, para a determinação da quantidade de matéria seca por hectare. A cobertura vegetal do solo foi avaliada pelo método de transecção linear, adaptado de Alves et al. (1998), em que corda com 10 metros de comprimento contendo 100 pontos espaçados de 10 $\mathrm{cm}$ foi estendida sobre o solo semanalmente. $\mathrm{O}$ número de pontos que sobrepunham resíduos vegetais foi considerado a porcentagem de cobertura do solo. As densidades do solo foram determinadas através do método do anel ou cilindro volumétrico (ЕмBRAPA, 1997), utilizando anéis de 2,6 cm de altura por 4,8 cm de diâmetro, volume de $47 \mathrm{~cm}^{3}$. As avaliaçôes do solo foram feitas nas camadas zero a $5 \mathrm{~cm}, 5$ a $10 \mathrm{~cm}$ e 10 a $20 \mathrm{~cm}$. A macroporosidade e a microporosidade foram determinadas utilizando-se câmara de pressão de Richards, considerando a pressão de $6 \mathrm{KPa}$ o limite para a retirada de água dos macroporos.

A estabilidade dos agregados foi obtida mediante de peneiramento em água, utilizando-se oscilador vertical de amplitude de $8 \mathrm{~cm}$ e frequência de 40 oscilaçōes por minuto. Baseando-se em Kemper e Chepil (1965) e nas adaptaçóes propostas por Reichert et al. (1993), EMbrapa (1997), Castro Filho et al. (1998), Palmeira et al. (1999) e Sá et al. (2000), Utilizaram-se amostras de aproximadamente 25 $\mathrm{g}$, que foram pré-umedecidas e colocadas no aparelho oscilador por 12 minutos. As fraçóes separadas foram os agregados $>2,00 \mathrm{~mm} ; 2,00-1,00 \mathrm{~mm} ; 1,00-0,50 \mathrm{~mm} ; 0,50-0,25 \mathrm{~mm}$; $0,25-0,105 \mathrm{e}<0,105 \mathrm{~mm}$. Com estes valores, calcularam o diâmetro médio ponderado (DMP) e o diâmetro médio geométrico (DMG). Os teores de carbono foram determinados por oxidação via úmida (EMBrapa, 1997).

A cultura de milho foi utilizada como indicadora da qualidade do solo. Após o florescimento, foi medida a altura de planta, altura de inserção de espiga e diâmetro de colmo, tomados em cinco plantas por parcela. A colheita foi feita manualmente em uma amostra de duas linhas de $5 \mathrm{~m}$ de comprimento em triplicata dentro da parcela. Foram ainda avaliados o comprimento e o diâmetro de espiga, o número de grãos por espiga e a massa de cem grăos.

Considerando o delineamento com três blocos casualizados, cinco tratamentos constituídos de culturas de inverno casualizadas dentro do bloco não se podem casualizar as três camadas avaliadas. Neste sistema, segundo Piepho et al. (2004), a unidade experimental é a parcela, caracterizada pela cultura $i$ no bloco $j$ e as camadas sáo repetidas dentro de cada unidade experimental. Múltiplas respostas tomadas em uma sequência (temporal ou espacial) em uma mesma unidade experimental são referidas como medidas repetidas e tendem a ser correlacionadas, gerando correlações dos erros e complicadas estruturas das matrizes de covariância. LitTell et al. (1998) recomenda a utilização do procedimento MIXED do SAS (SAS,

Tabela 1. Sistemas de sucessão de culturas nas parcelas avaliadas nos anos agrícolas de 2004/2005 e 2005/2006. Dourados (MS), 2007

\begin{tabular}{|c|c|c|c|c|}
\hline \multirow{2}{*}{ Sistemas } & \multicolumn{2}{|c|}{ Ano agrícola 2004/2005 } & \multicolumn{2}{|c|}{ Ano agrícola 2005/2006 } \\
\hline & Verão & Outono/Inverno & Verão & Outono/Inverno \\
\hline 1 & Soja & Girassol & Milho & Ervilhaca peluda \\
\hline 2 & Soja & Crotalária & Milho & Crotalaria \\
\hline 3 & Soja & Ervilhaca peluda & Milho & Girassol \\
\hline 4 & Soja & Crotalaria+Aveia & Milho & $\mathrm{EP}+\mathrm{NF}+\mathrm{AP}$ \\
\hline 5 & Soja & $E P+N F+A P$ & Milho & Crotalaria+Aveia \\
\hline 6 & Milho & Girassol & Soja & Ervilhaca peluda \\
\hline 7 & Milho & Crotalária & Soja & Crotalaria \\
\hline 8 & Milho & Ervilhaca peluda & Soja & Girassol \\
\hline 9 & Milho & Crotalaria+Aveia & Soja & $\mathrm{EP}+\mathrm{NF}+\mathrm{AP}$ \\
\hline 10 & Milho & $E P+N F+A P$ & Soja & Crotalaria+Aveia \\
\hline
\end{tabular}

$\mathrm{EP}=$ ervilhaca peluda, $\mathrm{NF}=$ nabo forrageiro, $\mathrm{AP}=$ aveia preta. 
1999), utilizado para permitir o acesso às estruturas de covariância dos erros e correçóes dos graus de liberdade. Considerou-se a interação entre camada e bloco, já que a heterogeneidade dentro do solo é tal que diferenças de blocos não são as mesmas em cada camada. A correçấo dos graus de liberdade foi feita pelo método de Kenward e Rogers (1997) (Comando no SAS: DDFM=KR). As médias de tratamentos e de camadas foram comparadas pelo método da estimação dos mínimos quadrados e utilizando a correção de Tukey.

\section{RESULTADOS E DISCUSSÃO}

Houve efeito significativo dos tratamentos nos atributos macroporosidade, microporosidade e porosidade total nas camadas de solo, nos dois anos avaliados. A macroporosidade foi maior na camada de 0 a $5 \mathrm{~cm}$, diferindo das camadas de 5 a $10 \mathrm{~cm}$ e de $10 \mathrm{a} 20 \mathrm{~cm}$, que não diferiram entre si. A microporosidade teve efeito contrário da macroporosidade, com valores menores na camada superficial, diferindo das outras duas camadas, que não diferiram entre si (Tabela 2). O resultado do volume total de poros foi semelhante ao da macroporosidade, com maiores valores na camada de 0 a $5 \mathrm{~cm}$. Considerando os dados do primeiro ano, os valores de macroporosidade foram $40 \%$ maiores na camada superficial em relação às camadas inferiores, enquanto os valores de microporosidade foram apenas $10 \%$ menores na camada superficial, fato que se repetiu no segundo ano.

A macroporosidade é um atributo importante para o desenvolvimento radicular e consequentemente das plantas. Valores de macroporosidade devem ser de pelo menos $10 \%$ do volume total do solo para permitir as trocas gasosas e líquidas entre o solo e a atmosfera (Xu et al., 1992). $\mathrm{Na}$ tabela 2 observa-se que os valores de macroporosidade na primeira safra foram superiores a este índice em todas as camadas, sendo o dobro na camada de $0 \mathrm{a} 5 \mathrm{~cm}$. Porém, na segunda safra, a macroporosidade foi menor. WoHLENBERG et al. (2004) verificaram que a sequência de culturas com a sucessão de gramíneas com leguminosas favoreceu a maior agregaçáo do solo. Os autores atribuíram este comportamento ao sistema radicular da gramínea e à taxa de decomposição da leguminosa, criando ambiente favorável à agregação pela ação das raízes, cobertura do solo, fornecimento de material orgânico e conservação da umidade favorável à ação dos microrganismos.

Houve diferença significativa nos valores de densidade, nos dois anos, em função dos tratamentos apenas para as camadas. $\mathrm{Na}$ camada de 0 a $5 \mathrm{~cm}$ os valores foram menores que os obtidos nas camadas de 5 a $10 \mathrm{~cm}$ e de 10 a $20 \mathrm{~cm}$. (Tabela 2). A densidade do solo é um indicador importante da qualidade física do solo, de fácil e rápida determinação, e pode ser usado para comparações entre situaçôes distintas ou entre diferentes camadas. ARgENTON et al. (2005), trabalhando em Latossolo Vermelho argiloso, verificaram aumento da densidade e diminuiçẫo da porosidade total da camada de 0 a $5 \mathrm{~cm}$ para as camadas mais profundas. Pesquisa desenvolvida por Rosolem et al., (1999) concluiu que as raízes de milho podem ser prejudicadas pelo aumento da densidade do solo, principalmente em solos argilosos, portanto, práticas que melhorem esta característica são desejáveis no sistema agrícola. FonseCA et al. (2007) observaram que o sistema de rotação que incluía a consorciação soja e braquiária, proporcionou menor densidade do solo e maior macroporosidade que a consorciação milho e braquiária em virtude, sem dúvida, do aumento, tanto de nitrogênio como de carbono orgânico no solo.

O SPD ao manter em torno de cinco a seis toneladas de palha na superfície do solo proporciona diminuição da densidade da camada superficial, contribuindo para a infiltração de água e aeração, favorecendo o desenvolvimento do sistema radicular. No trabalho de Braida et al. (2006), a presença de palha na superfície do solo igual ou superior a $4 \mathrm{Mg} \mathrm{ha}^{-1}$ resultou em dissipação da energia de compactação e menor densidade na camada de 0 a $5 \mathrm{~cm}$, quando comparada com solo sem presença de palha. Estes efeitos são mais pronunciados em solo argiloso do que em arenoso, devido à maior interação da matéria orgânica com as partículas de argila.

Segundo Argenton et al. (2005), quando a densidade do solo for superior a $1,30 \mathrm{~g} \mathrm{~cm}^{-3}$, devem-se usar práticas de cultivo que favoreçam o crescimento do sistema radicular e reduzam a densidade. Por outro lado, Reinert et al. (2001) indicam que para solos argilosos somente os valores de densidade acima de $1,45 \mathrm{~g} \mathrm{~cm}^{-3}$ são críticos ao crescimento radicular. A manutençáo da arquitetura

Tabela 2. Valores de macroporos, microporos e volume total de poros, nas três camadas de profundidades $(0$ a $5 \mathrm{~cm}, 5$ a $10 \mathrm{~cm}$ e 10 a 20 $\mathrm{cm})$ e nos dois anos avaliados. Dourados (MS), 2007

\begin{tabular}{ccccccc} 
Ano & Profundidade & Densidade do solo & Macroporos & \multicolumn{2}{c}{ Microporos } & Porosidade total \\
\cline { 2 - 6 } & $\mathbf{c m}$ & $0-5$ & $1,26 \mathrm{a}$ & $20 \mathrm{a}$ & $38 \mathrm{~b}$ & $58 \mathrm{a}$ \\
Ano 1 & $5-10$ & $1,41 \mathrm{~b}$ & $12 \mathrm{~b}$ & $42 \mathrm{a}$ & $54 \mathrm{~b}$ \\
& $10-20$ & $1,40 \mathrm{~b}$ & $12 \mathrm{~b}$ & $42 \mathrm{a}$ & $54 \mathrm{~b}$ & $59 \mathrm{a}$ \\
& $0-5$ & $1,27 \mathrm{a}$ & $14 \mathrm{a}$ & $45 \mathrm{~b}$ & $55 \mathrm{~b}$ \\
Ano 2 & $5-10$ & $1,44 \mathrm{~b}$ & $8 \mathrm{~b}$ & $47 \mathrm{a}$ & $56 \mathrm{~b}$
\end{tabular}

Médias seguidas de mesma letra, dentro de ano, năo diferem pelo teste Tukey $(\mathrm{p}<0,05)$. 
de poros e a permanência intacta dos restos de raízes das culturas, associada à ação da meso e macrofauna na fragmentaçáo dos resíduos e formação de galerias, favorecem a aeração e o movimento da água, resultando em trocas mais intensas e melhorando a agregação (CASTro Filho et al., 1998).

O teor de carbono orgânico teve diferenças significativas entre camadas e entre tratamentos. Na camada superficial observaram-se maiores valores que diminuem com a profundidade (Tabela 3). Esses resultados devem-se ao fato de que a permanência de palha e o não-revolvimento do solo no sistema plantio direto têm fundamental importância para o acúmulo de carbono na superfície do solo. No primeiro ano, nas parcelas com girassol e crotalária constataram-se os maiores valores de carbono orgânico, enquanto nas parcelas com ervilhaca e a mistura de aveia, ervilhaca e nabo, os menores. Já no segundo ano, nas parcelas com a mistura de crotalária + aveia notaram-se os maiores valores de carbono orgânico e nas parcelas com crotalária, os menores (Figura 1).
A matéria orgânica do solo é fundamental na ciclagem de nutrientes, na complexaçáo de metais e na atividade da biota do solo, portanto sua presença nas camadas mais superficiais, onde se concentra grande parte do sistema radicular, é um aspecto benéfico no sistema agrícola (Braida et al., 2006). A suscetibilidade de um solo a compactação torna-se menor à medida que se aumenta a quantidade de resíduo vegetal na superfície do solo, conforme pode ser observado nas tabelas 2 e 3, corroborando os resultados apresentados por BraIDA et al. (2006). A presença de palha na superfície do solo igual ou superior a $4 \mathrm{Mg} \mathrm{ha}^{-1}$ resultou em dissipação da energia de compactação e menor densidade na camada de 0 a $5 \mathrm{~cm}$, quando comparada com solo sem presença de palha.

A estabilidade de agregados tem sido utilizada como indicador da qualidade física do solo, pois é sensível às alteraçôes, conforme o manejo adotado (WENDLING et al., 2005). As avaliações da agregação do solo, representadas pelo diâmetro médio ponderado (DMP), diâmetro médio geométrico (DMG) e agregados maiores que 2

Tabela 3. Médias de diâmetro médio ponderado (DMP), diâmetro médio geométrico (DMG), porcentagem de agregados maiores que 2 mm (>2 mm) e carbono orgânico total (COT) nas três camadas e nos dois anos. Dourados (MS), 2007

\begin{tabular}{|c|c|c|c|c|c|c|c|c|}
\hline \multirow{3}{*}{ Camada } & \multicolumn{4}{|c|}{ Ano 1 (2004/2005) } & \multicolumn{4}{|c|}{ Ano $2(2005 / 2006)$} \\
\hline & СОT & DMP & DMG & $>2 \mathrm{~mm}$ & СOT & DMP & DMG & $>2 \mathrm{~mm}$ \\
\hline & $\mathbf{g ~ k g}^{-1}$ & \multicolumn{2}{|c|}{$\mathrm{mm}$} & $\%$ & $\mathbf{g ~ k g}^{-1}$ & \multicolumn{2}{|c|}{$\mathrm{mm}$} & $\%$ \\
\hline 0 a $5 \mathrm{~cm}$ & $23,12 \mathrm{a}$ & $3,92 \mathrm{a}$ & $1,49 \mathrm{a}$ & $62,36 \mathrm{a}$ & $19,76 \mathrm{a}$ & $3,53 \mathrm{a}$ & $1,36 \mathrm{a}$ & $55,38 \mathrm{a}$ \\
\hline 5 a $10 \mathrm{~cm}$ & $18,63 b$ & $2,73 b$ & $1,20 \mathrm{~b}$ & 37,94 b & $15,87 b$ & $2,94 b$ & $1,24 \mathrm{~b}$ & $42,72 \mathrm{~b}$ \\
\hline 10 a $20 \mathrm{~cm}$ & $16,94 \mathrm{c}$ & $2,30 \mathrm{c}$ & $1,11 \mathrm{~b}$ & $28,90 \mathrm{c}$ & $13,76 \mathrm{c}$ & $2,62 b$ & $1,18 b$ & $35,36 \mathrm{~b}$ \\
\hline
\end{tabular}

Médias seguidas pela mesma letra na coluna, não diferem entre si pelo teste Tukey $(\mathrm{p}<0,05)$.

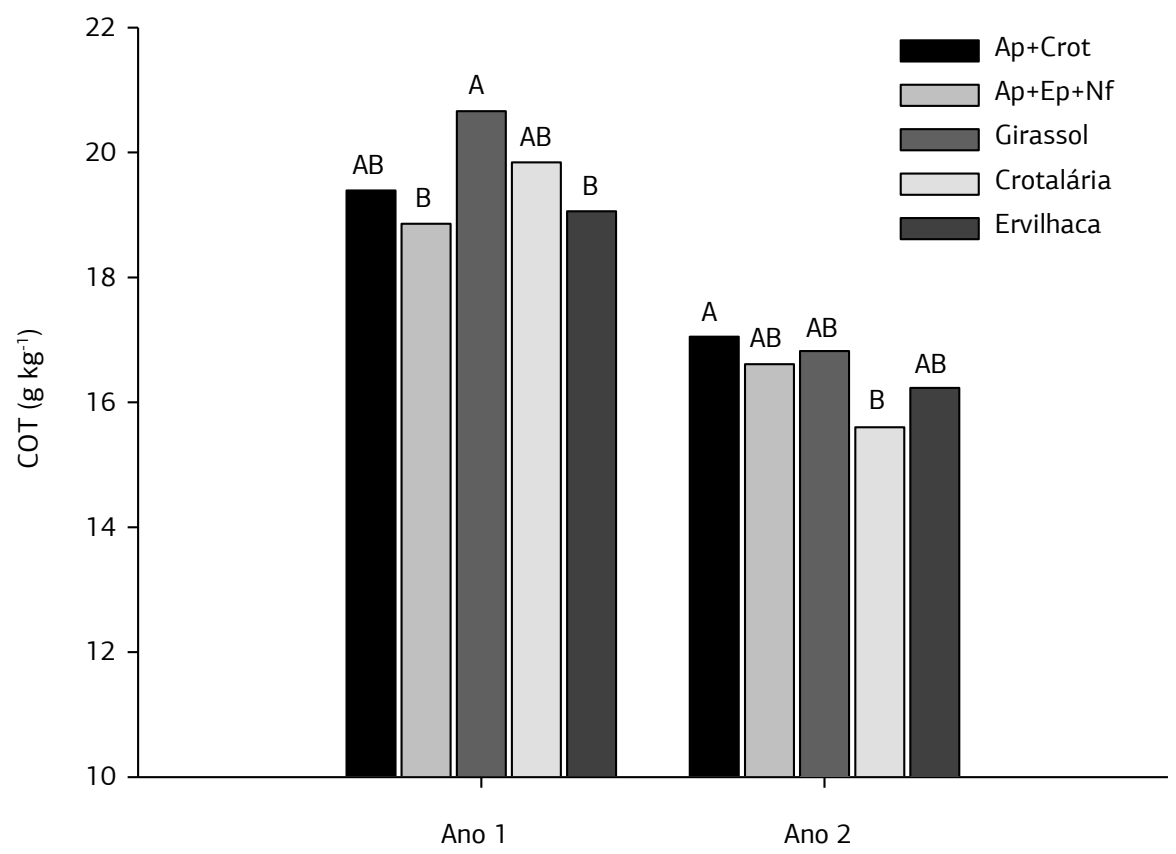

$\mathrm{Ap}=$ aveia preta, $\mathrm{Crot}=$ crotalária, $\mathrm{Ep}=$ ervilhaca peluda, $\mathrm{Nf}=$ nabo forrageiro

Figura 1. Médias de teor de carbono orgânico total (COT) para as cinco culturas antecessoras e nos dois anos avaliados. Dourados (MS), 2007. 
$\mathrm{mm}$, tiveram efeito significativo $(\mathrm{p}<0,01)$ somente para as camadas do solo, não havendo diferenças significativas para as sucessốes de culturas, nos dois anos avaliados.

$\mathrm{Na}$ distribuição dos agregados pelas classes de tamanho (Figura 2), observa-se alta proporção de agregados maiores que $2 \mathrm{~mm}$ na camada de 0 a $5 \mathrm{~cm}$, que diminui com a profundidade. Por outro lado, a proporção dos agregados menores, principalmente das classes de 1 a $2 \mathrm{~mm}, 0,5$ a $1 \mathrm{~mm}$ e de 0,25 a $0,5 \mathrm{~mm}$, aumentam com a profundidade, devido à redução na proporção da classe $>2 \mathrm{~mm}$. Os resultados do DMP e DMG (Tabela 3) têm a mesma tendência dos agregados maiores que 2 $\mathrm{mm}$, devido à maior contribuiçẫo desta classe de agregados nos cálculos de DMP e DMG. Stone e Guimaräes (2005) também constataram maiores valores de diâmetro médio ponderado na camada superficial $(0-5 \mathrm{~cm})$ do que nas inferiores.

Como pode ser visto pelos índices de correlação entre o carbono orgânico total e os índices de agregaçáo (Figura 3 ), quanto maiores os valores de carbono maior a agregação do solo. Os resultados de agregação acompanharam os teores de carbono nas camadas, já que o carbono orgânico é fundamental na agregação e estabilização dos agregados, principalmente os macroagregados. (Reichert et al., 1993; Castro Filho et al., 1998; Palmeira et al., 1999; SÁ et al., 2000; Wohlennerg et al., 2004; WendLing et al., 2005; Ferreira et al., 2007).

Segundo Stone e Guimaráes (2005), as diferenças nos atributos físicos do solo entre diferentes sistemas de rotação de culturas podem estar relacionados com a capacidade de cada sistema em alterar o conteúdo de matéria orgânica do solo. A diferença nos teores de carbono entre as culturas (Figura 1), não foram suficientes para refletir as diferenças nos valores de agregação do solo entre os tratamentos. A diferença do teor de carbono entre a camada 0 a $5 \mathrm{~cm}$ e a camada 5 a $10 \mathrm{~cm}$, no primeiro ano, que permitiu diferenças significativas entre os índices de agregação foi de $4,5 \mathrm{~g} \mathrm{~kg}^{-1}$, enquanto a diferença entre o maior valor (girassol) e o menor valor (aveia preta +ervilhaca peluda+nabo forrageiro) de carbono nos tratamentos no primeiro ano foi de apenas $1,8 \mathrm{~g} \mathrm{~kg}^{-1}$.

CAmpos et al. (1999) citam que pequenas variaçôes nos teores de carbono do solo podem não indicar diferença significativa na estabilidade de agregados. NASCIMENTO et al. (2005), estudando 12 espécies de leguminosas, também observaram diferenças entre o carbono do solo, a densidade do solo, a porosidade total e a agregação do solo somente entre as camadas de solo e não verificaram diferenças entre os tratamentos. Albuquerque et al. (2005) constataram diferenças nos teores de carbono orgânico do solo entre diferentes culturas consorciadas com o milho em Latossolo Vermelho Distroferrico, mas não houve diferenças nos valores de DMP. Os autores associam as diferenças nos teores de carbono aos aportes de massa seca produzida pelas culturas, sendo maiores os teores de C nos tratamentos com maior produção de massa.

As diferenças observadas nos teores de carbono do solo entre as culturas deste experimento também podem ser explicadas pelas diferenças entre a produçáo de massa seca das culturas de inverno, pois houve uma correlaçáo de $0,66^{* *}$ no primeiro ano e de $0,89^{* *}$ no segundo ano. Wohlenberg et al. (2004) estudando diversos sistemas de culturas verificaram maior percentagem de agregados em sistemas que proporcionaram aumento nos teores de matéria orgânica do solo, enquanto sistemas sem cobertura do solo, provocaram diminuiçáo dos teores de

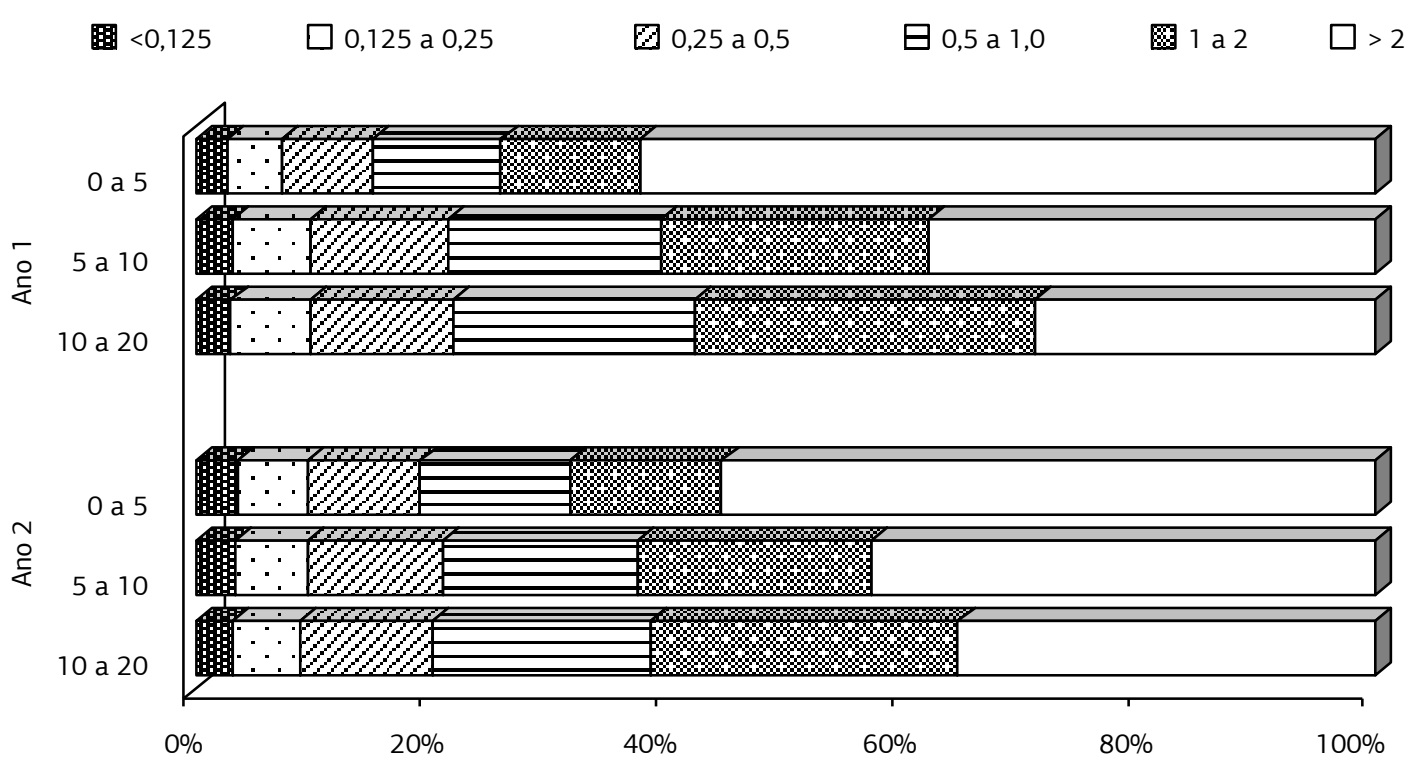

Figura 2. Distribuiçấo relativa dos agregados do solo por classes de tamanho, nas três camadas e nos dois anos avaliados. Dourados (MS), 2007. 
carbono do solo e da porcentagem de agregados maiores que $2 \mathrm{~mm}$. Campos et al. (1999), estudando gramíneas e leguminosas como culturas antecessoras ao milho, concluíram que plantas com produção maior de resíduos proporcionaram melhor agregação. WoHLEnBerG et al. (2004), trabalhando com cinco sistemas de sucessão/ rotação, incluindo leguminosas, gramíneas e crucíferas, chegaram às mesmas conclusões.

Comparando-se a produçáo de massa seca de cobertura, pode-se observar que o girassol teve maior produção de massa nos dois anos; a Crotalária produziu maior quantidade de massa seca no primeiro ano, porém, foi a que deixou menor quantidade no segundo ano (Tabela 4). No segundo ano, a Crotalária proporcionou baixo estande em função da qualidade da semente. Porém, a cobertura do solo com estas culturas, desde a emergência do milho, é menor do que das outras culturas nos dois anos (Figura 4). Esse fato ocorreu em funçáo de não haver uma relaçáo direta entre a massa de resíduos vegetais (Tabela 4) com o percentual
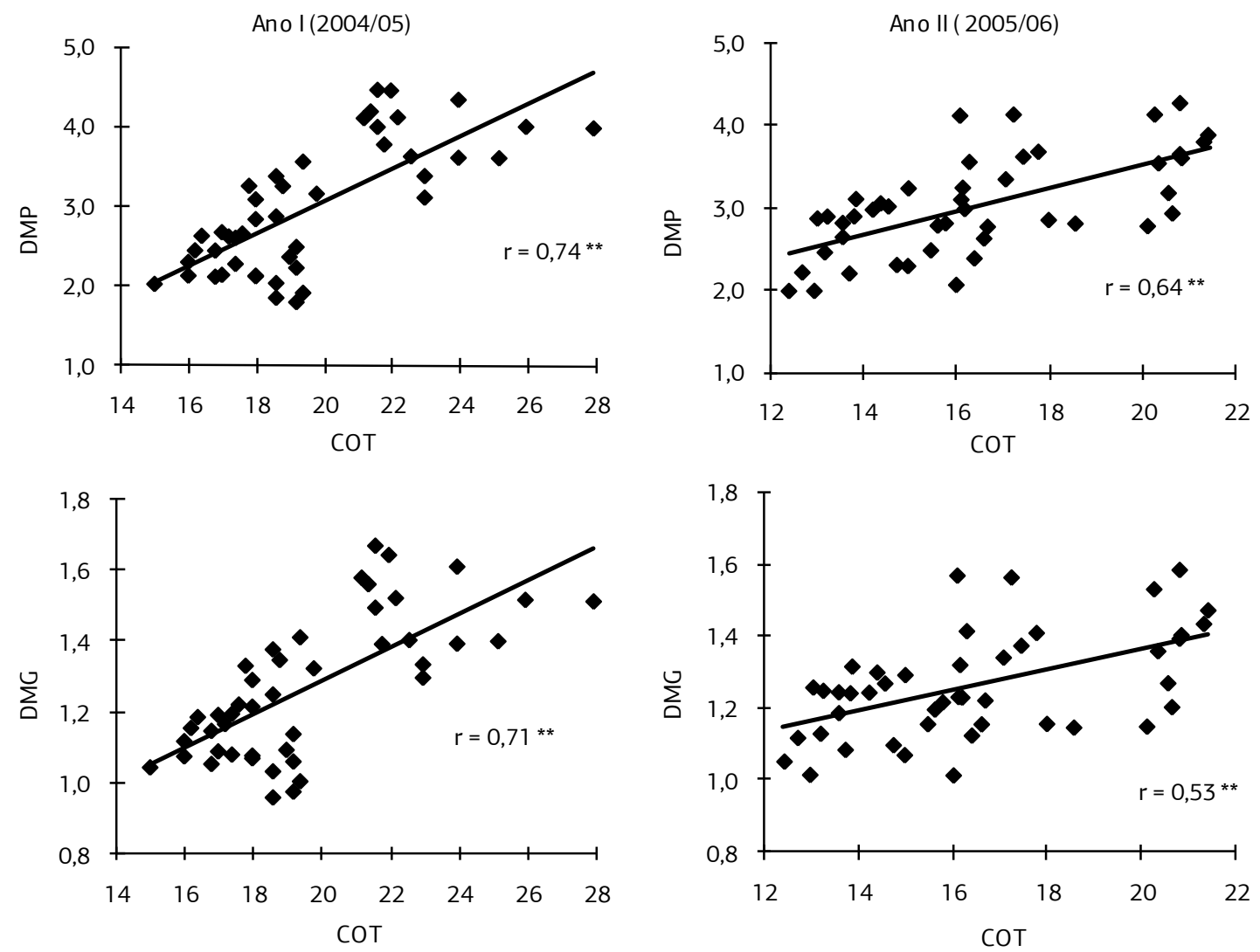

Figura 3. Correlações entre diâmetro médio ponderado (DMP) e diâmetro médio geométrico (DMG) dos agregados com o carbono orgânico total (COT) nos dois anos de estudo. Dourados (MS), 2007.

Tabela 4. Massa seca de cobertura e equação ajustada da cobertura do solo em função do tempo, proporcionada pelos resíduos das culturas antecessoras, nos dois anos avaliados. Dourados (MS), 2007

\begin{tabular}{|c|c|c|c|c|}
\hline \multirow{2}{*}{\multicolumn{2}{|c|}{ Culturas Antecessoras }} & Massa de Cobertura & Equação ajustada & $\mathbf{R}^{2}$ \\
\hline & & \multicolumn{3}{|c|}{$\mathrm{kg} \mathrm{ha}^{-1}$} \\
\hline \multirow{5}{*}{ Ano 1} & Crot + Ap & 3.325 & $\hat{y}=110,50 e^{-0,0149 x}$ & $0,86^{*}$ \\
\hline & $A p+E p+N f$ & 3.912 & $\hat{y}=116,13 e^{-0,0115 x}$ & $0,90^{*}$ \\
\hline & Girassol & 5.527 & $\hat{y}=56,40 e^{-0,0075 x}$ & $0,83^{*}$ \\
\hline & Crotalária & 4.015 & $\hat{y}=56,58 e^{-0,0092 x}$ & $0,85^{*}$ \\
\hline & Ervilhaca & 4.587 & $\hat{y}=130,76 e^{-0,0204 x}$ & $0,92^{*}$ \\
\hline \multirow{5}{*}{ Ano 2} & Crot + Ap & 4.693 & $\hat{y}=120,20 e^{-0,0103 x}$ & $0,92^{*}$ \\
\hline & $\mathrm{Ap}+\mathrm{Ep}+\mathrm{Nf}$ & 4.703 & $\hat{y}=115,83 e^{-0,0150 x}$ & $0,96^{*}$ \\
\hline & Girassol & 5.882 & $\hat{y}=30,97 e^{-0,0128 x}$ & $0,94^{*}$ \\
\hline & Crotalária & 2.271 & $\hat{y}=52,20 e^{-0,0141 x}$ & $0,93^{*}$ \\
\hline & Ervilhaca & 3.127 & $\hat{y}=91,87 e^{-0,0146 x}$ & $0,93^{*}$ \\
\hline
\end{tabular}

Crot $=$ crotalária, $\mathrm{AP}=$ aveia preta, $\mathrm{EP}=$ ervilhaca peluda, $\mathrm{NF}=$ nabo forrageiro, 

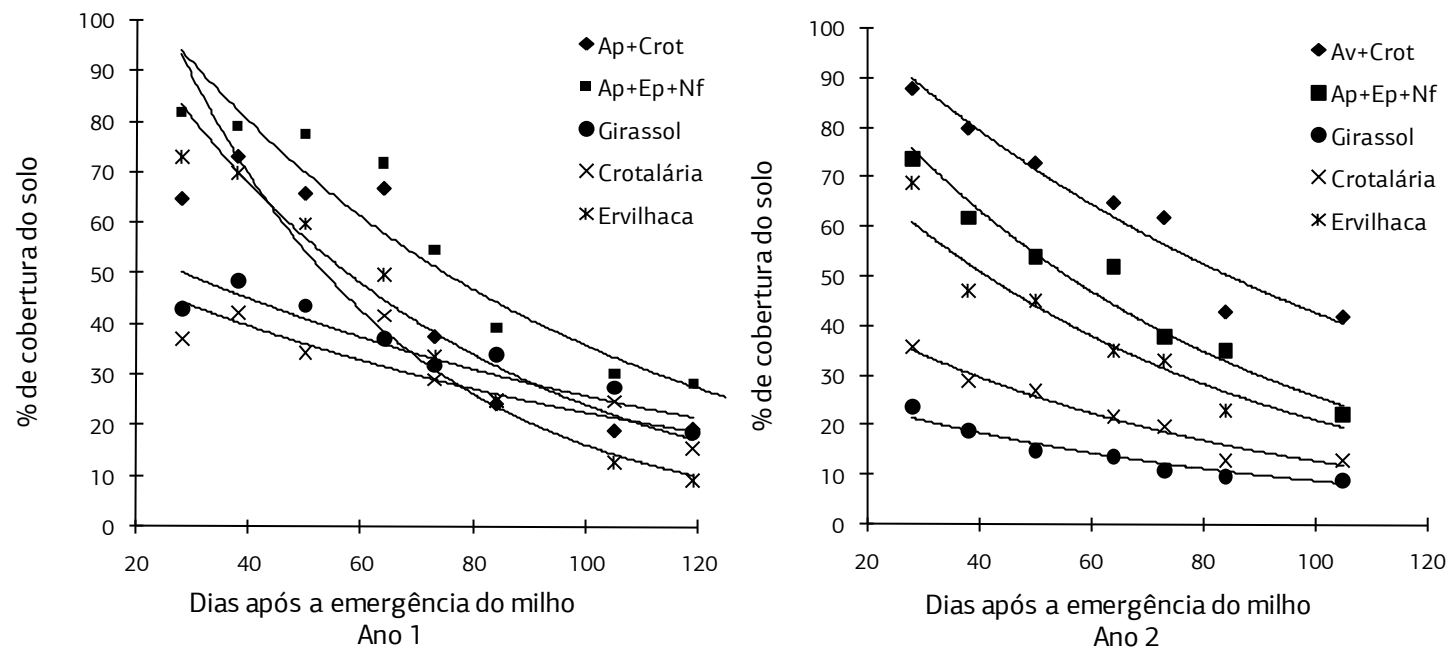

$\mathrm{Ap}=$ aveia preta; Crot=crotalária; $\mathrm{Ep}=$ =ervilhaca peluda; $\mathrm{Nf}=$ nabo forrageiro

Figura 4. Porcentagem de cobertura do solo pelos resíduos das culturas de inverno nos dois anos avaliados. Dourados (MS), 2007.

de cobertura do solo (Figura 4). A ervilhaca, uma das maiores quantidades de resíduos deixados na superfície e maior cobertura do solo, proporcionou uma cobertura semelhante à da crotalária e à do girassol aos 60 dias da emergência do milho, que coincidiu com a fase de pendoamento.

A explicação pode estar na relação $\mathrm{C} / \mathrm{N}$ e na lignificação dos resíduos que permanecem na superfície. Segundo Sodré Filho et al. (2004), os resíduos de crotalária e girassol têm alto teor de lignina e alta relação $\mathrm{C} / \mathrm{N}$ nos caules, sendo de 27 e 81 para crotalária e girassol respectivamente. Os mesmos autores confirmam a baixa cobertura destas duas espécies, devido à presença principalmente de caules e hastes, porém permanência maior na superfície do solo do que outras culturas. A relação $\mathrm{C} / \mathrm{N}$ da ervilhaca, por exemplo, é em torno de 19 (SÁ, 1993), o que acelera a decomposiçáo desta leguminosa. Nos dois anos avaliados, a ervilhaca foi a cultura com a maior taxa de decomposição (Tabela 4).

Os consórcios foram os tratamentos que menor quantidade de resíduos deixou no primeiro ano, porém no segundo ano, o comportamento foi diferente, com os consórcios deixando quantidades de resíduos maiores (Tabela 4). No primeiro ano, a cobertura do solo, no fim do ciclo do milho, foi semelhante entre as culturas estudadas, enquanto no segundo ano, observam-se maiores valores para os consórcios.

A produtividade de milho e as componentes de produçáo, nos dois anos avaliados, não tiveram diferenças significativas entre os tratamentos, e em 2004/2005 a média foi de $8057 \mathrm{~kg} \mathrm{ha}^{-1}$ e no ano 2005/06 foi de $3196 \mathrm{~kg} \mathrm{ha}^{-1}$. A menor produtividade observada em 2005/2006 foi devida ocorrência de veranicos. Lovato et al. (2004) também não observaram diferenças no rendimento de grão de milho cultivado após aveia, ervilhaca ou aveia + ervilhaca, desde que adicionado nitrogênio mineral na cultura de milho. Pasqualetto e Costa (2001) também não verificaram diferenças na massa de cem grãos e na produtividade de milho, quando este é cultivado após soja, girassol, milheto, sorgo ou guandu e recebe altas doses de adubo nitrogenado.

\section{CONCLUSÕES}

1. O sistema de plantio direto com aporte contínuo de palha minimiza a compactação do solo.

2. Os sistemas de culturas estudados são eficientes na produção de palha, e capazes de preservar os atributos físicos do solo.

3. Os consórcios entre aveia preta+ervilhaca peluda+nabo forrageiro e, da aveia preta+crotalária possibilitam maior cobertura e permanência da palha sobre o solo.

4. As culturas de girassol, crotalária e o consórcio aveia preta + crotalária proporcionam maiores teores de carbono orgânico total.

\section{AGRADECIMENTO}

Os autores agradecem a FUNDECT-MS pelo financiamento do trabalho.

\section{REFERÊNCIAS}

ALBUQUERQUE, J.A.; ARGENTON, J.; BAYER, C.; WILDNER, L.P.; KUNTZE, M. A. G. Relaçáo de atributos do solo com a agregação de um Latossolo Vermelho sob sistemas de preparo e plantas de verão para cobertura do solo. Revista Brasileira de Ciência do Solo, v.29, p.415-424, 2005. 
ALVES, A.G.C.; COGO, N.P.; LEVIEN, R. Comparação entre os métodos da transeção linear e fotográfico na avaliação de cobertura vegetal morta, sob dois métodos de preparo, após a colheita da soja. Revista Brasileira de Ciência do Solo, v.22, p.491-496, 1998.

ARGENTON, J.; ALBUQUERQUE, J.A.; BAYER, C.; WILDNER, L.P. Comportamento de atributos relacionados com a forma da estrutura de Latossolo Vermelho sob sistemas de preparo e plantas de cobertura. Revista Brasileira de Ciência do Solo, v.29, p.425-435, 2005.

BERTOL, I.; ALBUQUERQUE, J.A.; LEITE, D.; AMARAL, A.J.; ZOLDAN JÚNIOR, W.A. Propriedades físicas do solo sob preparo convencional e semeadura direta em rotação e sucessão de culturas, comparadas às do campo nativo. Revista Brasileira de Ciência do Solo, v.28, p.155-163, 2004.

BRAIDA, J.A.; REICHERT, J.M.; VEIGA, M.; REINERT, D.J. Resíduos vegetais na superfície e carbono orgânico do solo e suas relaçóes com a densidade máxima obtida no ensaio proctor. Revista Brasileira de Ciência do Solo, v.30, p.605-614, 2006.

CAMPOS, B.C.; REINERT, D.J.; NICOLODI, R.; CASSOL, L.C. Dinâmica da agregação induzida pelo uso de plantas de inverno para cobertura do solo. Revista Brasileira de Ciência do Solo, v.23, p.383-391, 1999.

CASTRO FILHO, C.; MUZILLI, O.; PODANOSCHI, A.L. Estabilidade dos agregados e sua relaçáo com o teor de carbono orgânico num Latossolo Roxo distrófico, em função de sistemas de plantio, rotaçóes de culturas e métodos de preparo das amostras. Revista Brasileira de Ciência do Solo, v.22, p.527-538, 1998.

EMBRAPA. Manual de métodos de análise de solo. Rio de Janeiro: EMBRAPA-Centro Nacional de Pesquisa de Solos, 1997. 212 p.

FERREIRA, F.P.; AZEVEDO, A.C.; DALMOLIN, R.S.D.; GIRELLI, D. Carbono orgânico, óxidos de ferro e distribuição de agregados em dois solos derivados de basalto no Rio Grande do Sul - Brasil. Ciência Rural, v.37, p.381-388, 2007.

FLOSS, E.L. Cobertura de inverno visando alto rendimento de culturas de verão. In: ENCONTRO REGIONAL DE PLANTIO DIRETO, 2., 2000, Ijuí. Resumos... Passo Fundo, 2000, p.29-43.

FOLONI, J.S.S.; LIMA, S.L.; BÜLL, L.T. Crescimento aéreo e radicular da soja e de plantas de cobertura em camadas compactadas de solo. Revista Brasileira de Ciência do Solo, v.30, p.49-57, 2006

Fonseca, G.C.; Carneiro, M.A.C.; Costa, A.R.; Oliveira, G.C.; Balbino, L.C. Atributos físicos, químicos e biológicos de Latossolo Vermelho distrófico de cerrado sob duas rotaçóes de cultura. Pesquisa Agropecuária Tropical, v.37, p.22-30, 2007.

KEMPER, W.D.; CHEPIL, W.S. Size distribution of aggregates. In: BLACK, C.A.; EVANS, D.D.; WHITE, J.L.; ENSMINGER, L.E.; CLARK, F.E. (Ed). Methods of soil analysis. Madison: American Society of Agronomy, 1965. p.511-519.

KENWARD, M.G.; ROGER, J.H. Small sample inference for fixed effects from restricted maximum likehood. Biometrics, v.53, p.983-997, 1997.
KOCHHANN, R.A. Alterações das características físicas, químicas e biológicas do solo sob sistema plantio direto. In: CONFERÊNCIA ANUAL DE PLANTIO DIRETO, 1., 1996. Passo Fundo. Resumos... Passo Fundo: Aldeia Norte, 1996. p 17-25.

KUSHWAHA, C.P.; TRIPATHI, S.K.; SINGH, K.P. Soil organic matter and water-stable aggragates under different tillage and residue conditions in tropical dryland agroecosystem. Applied Soil Ecology, v.16, p.129-241, 2001.

LITTELL, R.C.; HENRY, P.R.; AMMERMAN, C.B. Statistical analysis of repeated measures data using SAS procedures. Journal of Animal Science, v.76, p.1216-1231, 1998.

LOVATO, T.; MIELNICZUK, J.; BAYER, C.; VEZZANI, F. Adição de carbono e nitrogênio e sua relação com os estoques no solo e com o rendimento do milho em sistemas de manejo. Revista Brasileira de Ciência do Solo, v.28, p.175-187, 2004.

NASCIMENTO, J.T.; SILVA, I.F.; SANTIAGO, R.D.; SILVA NETO, L.F. Efeito de leguminosas nos atributos físicos e carbono orgânico de um Luvissolo. Revista Brasileira de Ciência do Solo, v.29, p.825-831, 2005

PALMEIRA, P.R.T.; PAULETTO, E.A.; TEIXEIRA, C.F.A.; GOMES, A.S.; SILVA, J.B. Agregaçáo de um Planossolo submetido a diferentes sistemas de cultivo. Revista Brasileira de Ciência do Solo, v.23, p.189-195, 1999.

PASQUALETTO, A.; COSTA, L.M. Influência de sucessão de culturas sobre características agronômicas do milho (Zea mays L.) em plantio direto. Pesquisa Agropecuária Tropical, v.31, p.61-64, 2001.

PIEPHO, H.P.; BÜCHSE, A.; RICHTER, C. A mixed modelling approach for experiments with repeated measures. Journal of Agronomy and Crop Science, v.190, p.230-247, 2004.

REICHERT, J.M.; VEIGA, M.; CABEDA, M.S.V. Índices de estabilidade de agregados e suas relaçóes com características e parâmetros de solo. Revista Brasileira de Ciência do Solo, v.17, p.283-290, 1993

REINERT, D.J.; REICHERT, J.M.; SILVA, V.R. Propriedades físicas de solos em sistema plantio direto irrigado. In: CARLESSO, R.; PETRY, M.T.; ROSA, G.M.; CERETTA, C.A., (Ed.). Irrigação por Aspersão no Rio Grande do Sul. Santa Maria, 2001. p.114133.

ROSOLEM, C. A.; FERNANDEZ, E. M.; ANDREOTTI, M.; CRUSCIOL, C. A. C. Crescimento radicular de plântulas de milho afetado pela resistência do solo à penetração. Pesquisa Agropecuária Brasileira, v.34, p.821-828, 1999.

SÁ, J.C.M. Manejo da fertilidade do solo. In: Plantio direto no Brasil. Passo Fundo: Aldeia Norte, 1993. p37.

SÁ, M.A.C.; LIMA, J.M.; SILVA, M.L.N.; DIAS JUNIOR, M.S. Comparação entre métodos para o estudo da estabilidade de agregados em solos. Pesquisa Agropecuária Brasileira, v.35, p.18251834,2000

SANTI, A.; AMADO, T.J.C.; ACOSTA, J.A.A. Adubação nitrogenada na aveia preta. I-Influência na produção de matéria 
seca e ciclagem de nutrientes sob sistema plantio direto. Revista Brasileira de Ciência do Solo, v.27, p.1075-1083, 2003.

SAS Institute Inc. SAS OnLine Doc, version eight. Cary, NC: SAS Institute, 1999.

SILVA, M.L.N.; CURI, N.; BLANCANEAUX, P. Sistemas de manejo e qualidade estrutural de Latossolo Roxo. Pesquisa Agropecuária Brasileira, v.35, p.2485-2492, 2000.

SODRÉ FILHO, J.; CARDOSO, A.N.; CARMONA, R.; CARVALHO, A.M. Fitomassa e cobertura do solo de culturas de sucessão ao milho na regiáo do cerrado. In: Pesquisa Agropecuária Brasileira, v.39, p.327-334. 2004

STONE, L.F. e GUIMARÁES, C.M. Influência de sistemas de rotação de culturas nos atributos físicos do solo. Santo Antônio de Goiás: Embrapa Arroz e Feijão, 2005. 15p.

TEIXEIRA, C.F.A.; PAULETTO, E.A.; SILVA, J.B. Resistência mecânica à penetraçáo de um argissolo amarelo distrofico típico sob diferentes sistemas de produção em plantio direto. Ciência Rural, v.33, p.1165-1167, 2003.

WENDLING, B; JUCKSCH, I.; MENDONÇA, E.S.; NEVES, J.C.L. Carbono orgânico e estabilidade de agregados de um Latossolo Vermelho sob diferentes manejos. Pesquisa Agropecuária Brasileira, v.40, p.487-494, 2005.

WILLIAMS, S.M; WEIL, R.R. Crop cover root channels may alleviate soil compaction effects on soybean crop. Soil Science Society of America Journal, v.68, p.1403-1409, 2004.

WOHLENBERG, E.V.; REICHERT, J.M.; REINERT, D.J.; BLUME, E. Dinâmica da agregação de um solo franco-arenoso em cinco sistemas de culturas em rotação e em sucessão. Revista Brasileira de Ciência do Solo, v.28, p.891-900, 2004.

XU, X.; NIEBER, J.L.; GUPTA, S.C. Compaction effect on the gas diffusion coefficient in soils. Soil Science Society American Journal, v.56, p.1743-1750, 1992. 